\title{
Etnografía en movimiento para explorar trayectorias de niños y jóvenes en Barcelona
}

\author{
Diana Arias ${ }^{1}$
}

Recibido: 4 de diciembre de 2015 / Aceptado: 12 de agosto de 2016

Resumen. Este artículo presenta la aplicación de una metodología móvil en el marco de una investigación sobre adopción. Acompañando a los participantes en sus recorridos cotidianos - caminando con ellos-, compartí los espacios públicos donde se movilizan las construcciones sociales por las que a veces son "confundidos" con "inmigrantes. Caminar con ellos me permitió acceder a la percepción que tienen los participantes sobre su ciudad, cómo la habitan y cómo la practican.

Se presenta la metodología del "recorrido acompañado", basada en otras metodologías móviles que se describen de forma sucinta - con especial énfasis en la literatura francesa menos conocida. Como resultado obtenemos una práctica de etnografía móvil que introduce Tecnologías de la Información y la Comunicación [TIC], se plantea desde la horizontalidad, valora el silencio, y hace acopio de las emergencias urbanas y el azar para acceder a informaciones vedadas a las preguntas directas e incluso a las indirectas.

Palabras claves: Etnografía urbana; metodologías móviles; jóvenes, niños; Barcelona.

\section{[en] Moving ethnography to explore children and youngsters trajectories in Barcelona}

\begin{abstract}
This article presents the application of a mobile methodology to a research focused on adoption. Accompanying the participants in their routines we shared public spaces where, due to social constructions, they are taken by "immigrants" because of their physical features. Walking with them also allowed me to gain access to their perception of the city and the way they live in.

This methodology is based on other 'mobile methodologies', which are briefly described in this article with an especial emphasis on French literature. As a result, we obtain a mobile ethnography that introduces Information and Communication Technologies [ICTs]; works from the horizontality; values the silence; collects urban emergencies and fate in order to have access to the information that is banned to direct and even indirect questions.
\end{abstract}

Keywords: Urban ethnography; Go-along; Children; Young people; Barcelona.

Sumario. 1. Introducción 2. El andar como fuente de conocimiento. 3. Metodología del recorrido acompañado. 4. Apertura lúdica de la metodología. 5. Singularidades de los trayectos urbanos en la construcción de la alteridad. 6. El paseo como digresión. 7. Memoria y silencio. 8. De la etnografía en movimiento a la dimensión resiliente del andar. 9. Referencias bibliográficas.

Cómo citar: Arias, D. (2017). Etnografía en movimiento para explorar trayectorias de niños y jóvenes en Barcelona, en Revista de Antropología Social 26(1), 93-112.

1 Grupo de investigación AFIN - Universitat Autònoma de Barcelona dyaryas@gmail.com 


\section{Introducción}

Las metodologías móviles están tomando auge en la investigación sobre la vida urbana y con ello asistimos a la revalorización de obras relativamente marginales hasta hace poco, las cuales ubican el andar en el centro de las reflexiones sobre los espacios públicos de nuestras sociedades. En ese marco, desplegamos aquí una etnografía en movimiento ${ }^{2}$, mediante la metodología del recorrido acompañado. Esta metodología fue aplicada en el contexto de una investigación sobre niños y jóvenes adoptados en Barcelona ${ }^{3}$, cuya meta era saber cómo enfrentan la paradoja que les convierte en "extranjeros en su propia ciudad", tal como argumentamos en otro lugar (Monnet, San Román, Marre, 2016). Los participantes de la etnografía estaban en el rango etario de 10 a 20 años - preadolescentes y adolescentes nacidos en diversos países-, a quienes acompañé en sus trayectos urbanos cotidianos ${ }^{4}$. Compartir esos trayectos me permitió ahondar en sus trayectorias personales (refiriéndome aquí a sus historias de vida), para entender cómo negocian su lugar en la sociedad catalana.

Presentando la metodología utilizada, se muestran algunos momentos de la "confusión" vivida por estos jóvenes que, debido a los signos visibles de haber nacido fuera de Cataluña y España, son asociados por otros barceloneses con las personas inmigradas ${ }^{5}$. Igualmente, el despliegue de la metodología hizo posible que me acercara a la visión de los participantes sobre la ciudad, las tensiones que observan, su sentido estético, sus cuestionamientos; así como las evitaciones y frecuentaciones derivadas de sus preferencias, su historia de vida, sus miedos, sus opiniones y su mirada crítica.

La tensión de la pertenencia o no pertenencia, tanto como las formas de habitar y practicar la ciudad de los peatones que intercambian de forma efímera ideas y prejuicios, se evidencia en los espacios públicos. Así, siguiendo a Alain Tarrius (1989), considero los trayectos urbanos como micro-fenómenos que visibilizan las singularidades y, al mismo tiempo, dan cuenta de las relaciones sociales. Los micro-

2 Me remito a la propuesta de Manuel Delgado de una antropología en movimiento para abordar los espacios urbanos. Delgado encuentra en el modelo cinematográfico la capacidad para la "observación directa de los aspectos materiales — verbales, gestuales, sonoros y corporales - de la actividad humana, es decir de la ritualidad de que se compone la vida cotidiana de las sociedades" (Delgado, 1999: 82)

3 Trabajo enmarcado en el proyecto I+D+I [CSO2012-39593-C02-01], financiado por el Ministerio de Economía y de Competitividad del Estado Español, tituladdo Adoptions and fosterages in Spain: tracing challenges, opportunities and problems in the social and family lives of children and adolescents; dirigido por la antropóloga Diana Marre. Dicho proyecto reagrupa más de 20 investigadores de distintas disciplinas. Se benefició de la experiencia de más de diez años de investigación del grupo AFIN sobre temas de adopción y se dividió en varios ejes de reflexión. Junto con Nadja Monnet estuvimos a cargo del que intentaba cruzar las variables:"jóvenes adoptados", "usos de los espacios públicos" y "estigmatización”. La ejecución del trabajo de campo fue responsabilidad mía, adaptando la metodología que he usado durante 10 años en diversas investigaciones.

4 No obstante, realicé una sesión de entrevista sedentaria — es decir, en posición fija: en la quietud de espacios privados, a saber, el comedor o el salón de su casa - como preámbulo de los trayectos. Esto constituyó un elemento de primera aproximación para entrar en contacto on las experiencias generales de uso del espacio público y negociar las modalidades de participación de los jóvenes y sus parientes en la investigación.

5 Esta "confusión" les ubica en un "fuera de lugar", que les lleva a experimentar la paradoja de la cercanía y la lejanía con la cual Georg Simmel describe la figura del extranjero: cercanos porque viven en la sociedad de la cual sus padres son originarios, pero lejanos en tanto son vistos como diferentes debido a sus características físicas. A pesar de tener un estatus legal de pleno derecho, a menudo se les pide justificar sus diferencias. Hemos optado por hablar de "fuera de lugar" más que de "entre-lugares" porque la adopción internacional introduce personas con estatus particular: a la vez dentro y fuera de la sociedad catalana, pero que han crecido en el seno de su intimidad (Monnet, San Román, Marre, 2016: 343). 
fenómenos implican para este autor una "puissance heuristique", es decir, potencia creadora, fuerza de conocimiento; son fuente de cambios, anticipadores de socializaciones, reorganizaciones del territorio, iniciadores de nuevas formas urbanas. Por tanto, como parte de la vida cotidiana de las ciudades, los trayectos pedestres están íntimamente relacionados con la trayectoria vital, la historia de vida, las preferencias, las categorizaciones, los deseos y la forma de asumir los códigos socio-culturales. Por ello, dados los prejuicios y estigmas que recaen sobre las personas adoptadas en Barcelona, en el trabajo de campo he privilegiado sus recorridos urbanos, entendidos como escenario de su agencia ${ }^{7}$ frente a esa estigmatización, pues considero que los usos del espacio público - y las interacciones que allí se dan — ofrecen elementos de análisis sobre las relaciones sociales y la construcción de la alteridad.

En ese sentido, los desplazamientos implican un movimiento dentro de las escalas de las construcciones sociales del otro. El transeúnte se percibe a sí mismo y a los otros ocupando un lugar en las jerarquías, lo cual implica auto-conciencia de la posición ocupada en esas jerarquías, susceptibles de ser alteradas a través de los deseos y las intenciones de quien se desplaza, utilizando "estrategias y tácticas" de frecuentación o de evitación (De Certeau, 1984: 57-63). Utilizar la herramienta del recorrido acompañado me permitió, por una parte, analizar su manera de aprehender el espacio urbano y observar sus negociaciones in situ y, por otra, acceder a sus historias de vida.

\section{El andar como fuente de conocimiento}

Diversos investigadores subrayan el valor epistemológico de las prácticas caminatorias. Autores como Jean-Francois Augoyard (1979), Michel de Certeau (1984), Pierre Sansot (1996), Isaac Joseph (1998), Jean-Yves Petiteau y Elisabeth Pasquier (2001), Jean-Paul Thibaud ${ }^{8}$ (2001), Paola Berenstein (2006 y 2012), De Biase (2006) han tratado el andar como método revelador de lo urbano. Remiten a la acción en curso e in situ del participante de la investigación y del etnógrafo que se deja guiar por su interlocutor en la cotidianidad de sus trayectos urbanos. En sus metodologías combinan narración y observación para explorar la percepción, las prácticas y la forma de habitar los territorios. Otras autoras como Marie-Axelle Granié (2010), Florence Huguenin-Richard (2010) o aún Pascale Legué (2015) se han centrado específicamente en los desplazamientos urbanos de niños no acompañados por adultos. En la literatura anglosajona también abundan trabajos basados en métodos móviles y centrados en la caminata. Autores como Pia Christensen y Margaret O'Brien (2003),

\footnotetext{
La traducción de las citas en francés e inglés es propia.

Entendemos por agencia el papel activo de los participantes de la investigación. Antes que verles como portadores de datos, que el investigador recoge, les abordamos como interlocutores que también guían la producción y construcción de conocimiento. Al resaltar este aspecto, queremos impugnar la visión de los preadolescentes y adolescentes como inmaduros y sin opinión. Desde allí, entablamos con ellos una relación que les concibe como "actores que crean su propia vida de forma activa [...] y muchas veces tienen visiones antagónicas de los usos del espacio público que comparten con los adultos" (Rasmussen y Smith, 2002: 2).

8 Este autor ha acuñado la metodología de los recorridos comentados para explorar la percepción en movimiento de los peatones en espacios públicos: caminar, percibir y describir. Aunque nuestra metodología de "recorridos acompañados" se acerca más al uso de los recorridos por parte de Augoyard (1979), Petiteau y Pasquier (2001), algunas de la reflexiones de Thibaud (2001) son relevantes en este trabajo trabajo, en cuanto privilegian los recorridos como herramienta de observación.
} 
Jon Anderson (2004); Margarethe Kusenbach (2010), Andrew Clark y Nick Emmel (2010) o Kim Rasmussen ${ }^{9}(2003,2014)$ abordan el espacio vivido y percibido durante el andar, convirtiéndolo en fuente de conocimiento sobre formas de practicar el espacio y actuar sobre él.

En todos los casos mencionados, el conocimiento - de los usos del espacio urbano- se construye a partir de los desplazamientos del interlocutor, quien se transforma en un guía que comparte las pautas de su cotidianidad espacial. Esto implica una co-producción del conocimiento que toma el caminar como ámbito de observación, prioriza la utilización del espacio urbano y tiene en cuenta la narración de los transeúntes mientras caminan.

Según Augoyard, dado que el contenido de la entrevista proviene de la memoria construida, las respuestas a un guión de preguntas resultan vagas en cuanto están apartadas de la experiencia sensorial directa. Nos ponen en contacto con un "collage" de recuerdos evocados por el entrevistado que trata de rememorar aquello que sucede mientras camina. Fuera del lugar original de la acción, la entrevista se queda corta comparado con la producción de las narrativas caminatorias, y dificulta el análisis de sus referentes y sus significados. En palabras de Kusenbach "Esto dificulta entender exactamente aquello de lo que están hablando los interlocutores — si son capaces y están dispuestos, por lo menos, a discutir aquello que los investigadores están interesados en hablar. En ambos casos, los aspectos importantes de la experiencia vivida también pueden - permanecer invisibles o, aunque se perciban, resultar ininteligibles" (Kusenbach, 2010: 459). Augoyard (1979) supera esta limitación con sus "retóricas habitantes" —rhétóriques habitantes - Lo hace abordando las especificidades de los trayectos cotidianos de los residentes de un suburbio francés - L'Arlequin, en Grenoble- . Con ello, ahonda en cómo se realizan los recorridos. Concluye que en sus trayectos, el transeúnte condensa el tiempo y el espacio de la ciudad, su historia de vida particular, sus reflexiones y deseos, resultando un conglomerado de signos materiales e inmateriales: el cuerpo, el camino, los pensamientos, los recuerdos, las emociones. Según Augoyard, "Los movimientos de apropiación suponen, como condición de posibilidad, la superación de los condicionamientos meramente espaciales que solo expresan las relaciones sociales bajo la forma de meros estados de las cosas. Estos movimientos implican una dinámica aprehendida en función del tiempo" (Augoyard, 2010: 113). Este investigador hace co-partícipes del trabajo de campo a sus interlocutores, pues les pide escribir sus recorridos e impresiones sobre el mismo. Luego el autor analiza las figuras literarias utilizadas en las narrativas de esas notas.

En la misma línea de privilegiar el recorrido como ámbito de observación, $\mathrm{Ku}$ senbach (2010) acuña la herramienta metodológica "go-along". Se trata de un ejercicio de fenomenología de la calle para acceder a los "aspectos trascendentes y reflexivos de la experiencia vivida in situ" (Kusenbach, 2010: 455). La herramienta "go-along" consiste en acompañar los recorridos de los participantes para entrar en el ámbito de su familiaridad, explorar su percepción del entorno, sus prácticas espaciales, su biografía, su utilización del espacio arquitectónico y las relaciones sociales. En síntesis, se trata de un acercamiento al sentido que tienen para el participante las prácticas cotidianas de movilidad en los espacios urbanos. En dicho acompañamiento, Kusenbach observa y pregunta en medio de las actividades habituales que realizan los participantes. Esto le permite acceder a matices individuales

Rasmussen introduce la fotografía para trabajar específicamente con niños. 
y detalles que podrían parecer insignificantes o pasar desapercibidos en el marco de una entrevista en posición sentado. Para la autora, esta herramienta requiere un papel muy activo del etnógrafo, pues debe observar cómo se ubican los interlocutores en el paisaje local-social, así como la relación entre los aspectos sensorial, psicológico, emocional, de gustos y experiencias previas, y las interacciones. Apela también a los contenidos simbólicos de los usos de la calle en cuanto hay un papel activo de la memoria como recuerdo, pero también como anticipación frente a los eventos fortuitos que activan el repertorio de experiencias previas: "Navegar en los ambientes familiares llenos de paisajes personales se asemeja en muchos aspectos a hojear las páginas de un álbum de fotos familiar o un diario personal" (Kusenbach, 2010: 472).

La polivalencia y la polisemia de los trayectos urbanos constituyen un entramado de sentido para investigador y participante. Esto lleva a Jean-Yves Petiteau y Elisabeth Pasquier a considerar su "método de los itinerarios" 10 como un "uso compartido del espacio". Su concepto de itinerario tiene dos acepciones: se refiere al resultado de este proceso metodológico de investigación [globalité de la recherche - globalidad de la investigación-] y al procedimiento en sí mismo [journée de l'itinéraire - día del itinerario- ], consistente en los recorridos realizados en terreno (JeanYves Petiteau y Elisabeth Pasquier, 2001: 63) — todo ello, después de una o varias entrevistas en profundidad en el domicilio del participante.

En síntesis, estas metodologías, propias de la etnografía en movimiento, implican un ejercicio de experiencia compartida; se insertan en el tránsito de los trayectos urbanos de los peatones y nos instalan en las interacciones, sus códigos de intercambio, las formas de hacer y pensar. Vinculados por el recorrido, participante y etnógrafo realizan un intercambio físico al compartir espacio y tiempo; también se da un diálogo durante la marcha en el que aparecen relatos, comentarios, emergencias de acontecimientos y desviaciones imprevistas que enriquecen la investigación, así como momentos de silencio frente a las preguntas o como parte del andar juntos que constituye el recorrido acompañado.

\section{Metodología del recorrido acompañado}

La metodología aquí presentada se nutre de los antecedentes anteriormente mencionados, combinándolos y reajustándolos en función de la temática de nuestro estudio. La primera variación consiste en utilizar varias tecnologías digitales [móviles, cámara de fotos y de vídeo] en las comunicaciones con los interlocutores y en el campo. Al contrario que en métodos de otros autores, estos dispositivos estaban bajo responsabilidad de una sola persona para conservar el grado de intimidad logrado por la presencia de un solo interlocutor. Aunque los equipos siempre están a mano, se utilizan de acuerdo con el momento y las características de los datos. La cámara de fotos es un elemento que víncula y media entre el participante y la etnógrafa para acceder a la percepción del espacio público; la cámara de video se utiliza para acciones en las cuales se realiza una observación no intrusiva - cuando se presentan interacciones en el camino. Estas variables dan información sobre la construcción de la ciudad por parte de niños y jóvenes. Asimismo, permiten crear espacios de proxi-

10 Esta metodología requiere un equipo conformado por un fotógrafo, un entrevistador y una persona encargada de la grabación de audio. 
midad y confianza que, también gracias al azar y los imprevistos de la vida cotidiana, se han convertido en oportunidades para llegar a testimonios vedados en otro tipo de aproximación cuando interrogamos sobre temas difíciles de abordar, como, en este caso, la estigmatización por el fenotipo.

El acompañamiento de recorridos (Diana Arias, 2000) implica abordar a los participantes desde una relación horizontal, en la cual ellos se convierten en guías de la investigación en el espacio público. Hablamos de una co-autoría en la producción de los datos, cuyo análisis realizamos a partir de esta concepción participativa de la investigación. Esta centralidad del caminar juntos es esencial en las metodologías de itinerarios y más concretamente cuando se trata de niños y jóvenes peatones, quienes son, según la expresión de Pascal Legué, "los olvidados de la ciudad": "su ciudad es la del peatón [...] a través de sus caminatas, sus miradas, su discurso pero también de lo no dicho, he[mos] aprehendido su mundo" (Legué, 2015: 46).

Los itinerarios y testimonios de nuestros interlocutores fueron centrales para la construcción del trabajo de campo. Estimamos fundamental valorar la capacidad de agencia de niños y jóvenes en la construcción y gestión del conocimiento: "Ellos construyen un universo personal en la ciudad que los adultos apenas sospechan" (Legué, 2015: 55). Su mirada, hedonista o crítica, de los espacios públicos permite explorar su visión del mundo, su capacidad de interlocución y su potencia para la observación de los territorios. Estos datos incluso pueden albergar insumos valiosos para las políticas públicas urbanas que tengan en cuenta la mirada de niños y jóvenes. Sus opiniones pueden aportar elementos para cambiar esa ciudad infantilizada que se les ofrece, o transformar otros temas que les preocupan, les asustan o que cuestionan, tales como la pobreza, los habitantes de la calle, el medio ambiente, la inequidad, la concepción de género, el tráfico urbano o la drogodependencia, entre otros. Por tanto, los recorridos acompañados de forma individual $-\mathrm{o}$ en grupos de dos - constituyen una aproximación al universo de referencias de niños y jóvenes.

Tal como se explicó en la nota a pie de página No.4, realicé un encuentro previo a los recorridos, en el que utilicé un guión de preguntas. Este nos sirvió para construir conjuntamente un inventario de los recorridos de cada participante y elegir aquellos que se iban a acompañar. Me pareció interesante realizar trayectos de distinta índole para observar diferencias. Realicé un mínimo de tres trayectos con cada uno de los participantes. Ellos se convirtieron en el faro de dos tipos fundamentales de recorridos cotidianos. En primer lugar, unos muy pautados y reglados, correspondientes a sus actividades escolares y extraescolares, con intermedios para comer en casa de los abuelos o para ir a casa de la madre o el padre. En segundo lugar, los relacionados con actividades de ocio en grupos de dos o más compañeros, en los cuales se desplazan mayoritariamente a pie — combinando a veces con transportes públicos — para ir al cine, a comer algo, jugar al fútbol, quedarse en una plaza o, en el caso de los más pequeños, para ir a jugar a parques y plazas de su barrio, donde coinciden con amigos de clase o vecinos del barrio ${ }^{11}$.

A pesar de estar enfocada en el tema de los prejuicios y la estigmatización, también he explorado los usos y percepciones del espacio público. Entregué una cámara fotográfica a los interlocutores para que hicieran capturas de lo que les llamaba

11 En la mayoría de los casos, los participantes se negaron a que les acompañara en estos trayectos —algunos dijeron que se sentirían avergonzados. No obstante, realizamos algunos, en los cuales la actitud de los chicos era diferente a cuando íbamos solos. 
la atención. Esto fue eficaz para explorar su percepción de los espacios públicos y generar complicidad durante las capturas y en el visionado de las imágenes. La mayoría de nuestros participantes se fijaba en cosas significativas de acuerdo con sus preferencias y también evocaban acontecimientos vividos en el pasado. El recorrido les ofrece una ciudad hecha de retazos porque "el caminar urbano está sembrado de espectáculos e incesantemente despierta nuestra curiosidad" (Le Breton, 2015: 85). Las preferencias y la personalidad determinan los focos de atención y los usos de cada transeúnte: "me gusta pasar por una tienda que hay una canción, por ejemplo, relajante, pum, se cambia a una canción de fiesta o a una canción de rock and roll, y pasa a una de rock" [Iván, 11 años] ${ }^{12}$; "Me gusta ver esta plaza llena de adornos de navidad" [Verónica, 12 años]; "Me gusta más el Paralelo donde hay muchos inmigrantes, es más humano y la gente es más próxima" [Laura, 20 años]; "me gusta mucho observar la gente y lo que hace en la calle" [Abril, 17 años]; "Preferimos estar en las escaleras del parque, hay menos gente" [David, 13 años].

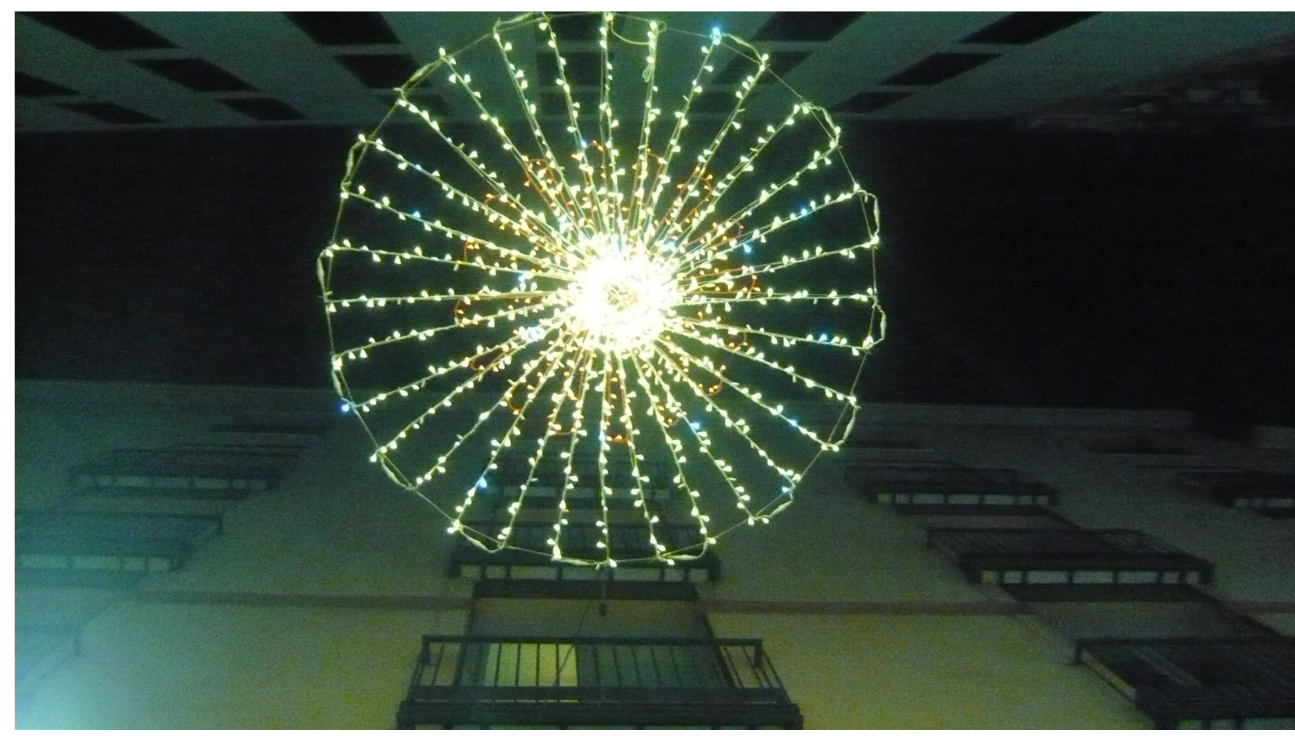

Imagen 1. El trabajo de campo se realizó a lo largo de diversas estaciones del año. La mayoría de los participantes exploraba la plasticidad de los adornos de navidad que transformaban sus recorridos cotidianos. Fotografía de Verónica [12 años].

\section{Apertura lúdica de la metodología}

Tal como sostienen Nathalie Audas y Denis Martouzet (2009: 62), "esta técnica se percibe como algo lúdico y, a menudo, desconocida por los participantes, tiene

12 Los nombres de nuestros interlocutores han sido cambiados para mantener el anonimato. 
la atracción de la novedad"13. Durante el acompañamiento de los recorridos, la mayoría de los participantes mostraron una sonrisa cómplice con la presencia de la grabadora de sonido o frente a las cámaras de registro de imágenes fijas y en movimiento; la sensación de episodio divertido genera acercamiento, especialmente de los más jóvenes. Uno de los participantes comentó a su madre que se sentía "como si fuera un político" [Javier, 13 años]. Otro de ellos, cuando sus compañeros de fútbol le preguntaron por la presencia de un adulto que no conocían - de camino a los entrenamientos y durante ellos-, les contestó que era de la empresa Nike, pues le habían llamado de esa empresa para "hacerme un reportaje" [Alex, 15 años].

Este carácter de novedad y aspecto de ludicidad se transforma en una ventaja —no exenta de cambios en la relación etnógrafa/participante_- dar importancia a su persona, a sus palabras y a sus opiniones genera un vínculo empático, en el que el observador también es observado. Algunos de los participantes han hecho preguntas sobre el trabajo de campo, la metodología, mi trayectoria vital, el número de entrevistados, etc. Otros aportan observaciones etnográficas sobre lo que encuentran en los recorridos: en un barrio de clase alta donde las niñeras se encargan del cuidado de los niños, una de nuestras participantes comenta: "¿te has fijado que ninguna de las mujeres que van con los niños son sus madres?" [Laia, 20 años]; "Las personas han ido adaptando diferentes formas de vida y de vestimenta: las "chonis" — horteras, se ponen piercings_-, les gusta atraer a los chicos; los "frikis" - dicen cosas raras o se enganchan en un mismo tema-; los empollones son los normalitos; los "góticos" — se visten de negro, les gusta las calaveras, la sangre_-" [Sabina, 15 años].

El recorrido acompañado genera un espacio de comunicación al ritmo del camino — donde también se dan silencios, evocaciones o contemplaciones-, porque "el itinerario es una experiencia compartida entre el investigador y el otro" (Petiteau y Pasquier, 2001: 63). Esta metodología va más allá de los límites impuestos por la objetividad y la distancia porque caminar con el otro genera complicidad, y esta, a su vez, propicia el acceso a la proximidad que permite llegar donde no llegamos con las preguntas directas. Hablando con Iván [11 años] al regresar de su clase de música, propongo un ejercicio de imaginación sobre lo que estaría haciendo el resto de la gente mientras caminábamos hacia su casa; tras una serie de enumeraciones, agrega que algunos estarán haciendo deberes para la escuela. Le pregunto sobre sus deberes e inicia un relato sobre su trabajo de final de curso, revelando detalles sobre la estigmatización: el tema que ha elegido es la adopción. Quiere explicarles a sus compañeros qué es, por qué se adopta y cómo se da. Con ello quiere deconstruir las premisas de insultos del tipo: "tú cállate, que a ti te recogieron de la basura". Imprecaciones expresadas por compañeros de clase en situaciones de tensión y referidas al hecho de haber nacido en el extranjero y ser adoptado. En otro caso, Abril [17 años] hace una parada en nuestro recorrido para comer con su abuela. Al finalizar la comida, le enseña un libro recién publicado donde aparecen algunos de sus poemas. Más tarde, al retomar nuestra ruta, hablamos sobre su afición por la escritura y me habla de una novela corta que escribió un año atrás: un relato que narra episodios de abandono, olvido y reencuentro. La protagonista es adoptada y, por una serie de hechos fortuitos, se relaciona con un

13 Se refieren a la metodología de los "recorridos comentados" de Thibaud (2001), pero consideramos este comentario válido para nuestros "recorridos acompañados". 
hombre y una mujer en una trama llena de viajes. El desenlace de la obra develará que estas dos personas son su madre y padre biológicos, un hecho que reconocen y asumen los tres. Tanto Iván como Abril han expresado vivir la adopción sin problemas en momentos en que utilicé preguntas indirectas. Es el azar del camino y lo que sucede en su recorrido lo que nos muestra la estigmatización en la escuela o el deseo de conocer los vínculos biológicos no expresados explícitamente por algunos niños jóvenes adoptados.

Situaciones como las descritas permiten acceder a datos que serían difíciles de obtener mediante una entrevista cara a cara o una pregunta directa: el azar, el ritmo de los recorridos, las conversaciones triviales, el entorno de la calle, la complicidad - por nombrar algunas emergencias inusitadas - generan situaciones aparentemente desligadas del objetivo de la investigación. Sin embargo, ofrecen elementos para exploraciones más profundas que las obtenidas mediante lo explícito de un guión de búsqueda pre-establecido. Como muestran los testimonios anteriores, en ocasiones, accedemos por casualidad a informaciones vedadas a las preguntas directas e incluso a las indirectas.

\section{Singularidades de los trayectos urbanos en la construcción de la alteridad}

Los recorridos involucran las percepciones sensoriales, las interacciones y la memoria: olores, colores, sonidos, recuerdos, encuentros, desencuentros, sensaciones, pensamientos. Las trayectorias urbanas forman parte de la biografía de quien camina y de su relación con los lugares y las experiencias vividas: observarlas significa comprender "cómo las personas conectan e integran las diversas regiones de sus vidas e identidades cotidianas" (Kusenbach 2010: 478). La trayectoria vital impulsa al transeúnte a ejercer diferentes acciones que le llevan a la calle para realizar actividades personales, singulares, repetitivas o inéditas, las cuales forman parte de un proyecto de vida. Durante el recorrido, el cuerpo es pura potencialidad; porque el azar puede exigir que aflore cualquiera de las formas que puede adoptar, incluso algunas nunca probadas en su repertorio. Tal como dice Isaac Joseph "la marcha y el paseo instauran la primacía del instante aislado, la actividad no reflexionada e intransitiva donde el cuerpo se olvida" (Joseph, 1998: 19).

Las prácticas caminatorias en el espacio urbano son formas de habitar la ciudad, están inmersas en la cotidianidad. Parecieran pertenecer a la esfera de lo anodino, pero constituyen fragmentos de vida que conectan al transeúnte con el mundo y consigo mismo: "Puedo entrar con cinco personas más al supermercado y solo me revisan el bolso al mí" [Laura, nacida en Colombia, 20 años]; "mira, esta china de grande tendrá un bazar" [palabras dirigidas a Leticia, nacida en China, 14 años]. Este tipo de situaciones evidencian, primero, el lugar adjudicado por una parte de la población a las personas con aspecto físico distinto al considerado como "lo local", en este caso, a las personas inmigradas. En en segundo lugar, muestran las formas de agencia de nuestros interlocutores frente al trato desigual en la jerarquía social. Laura asume una defensa de la ciudadanía plena para los migrantes, mediante su participación como activista en la defensa de derechos; Leticia piensa que sus ojos rasgados son un obstáculo para ligar, mientras que sus hermanas [10 y 13 años] sienten tan invadida su intimidad que sienten vergüenza cuando son escrutadas como distintas por sus rasgos físicos. 
Constaté también que algunos de nuestros interlocutores han interiorizado prejuicios presentes en ciertas capas de la sociedad catalana. Así, varios de ellos hacen una distinción entre turistas e inmigrantes. Una de ellas considera culturalmente ricos a los turistas occidentales, cuyos países le gustaría visitar, mientras ve poco interesante la cultura de los ciudadanos de Pakistán, Marruecos, América Latina o los gitanos. Opinión contrapuesta a la de otra participante que considera a las personas inmigradas más "auténticas" que los turistas, a los que describe con la frase "todos son iguales".

La mayoría de los participantes se consideran catalanes y son de clase media alta. Han experimentado episodios de discriminación por su condición de adoptados, pero son tenidos en cuenta por sus grupos próximos como parte de un "nosotros" con el cual ellos se identifican. Se sienten pertenecientes a la sociedad catalana. Esta pertenencia recíproca - construida por lazos de proximidad: barrio, escuela, poder adquisitivo, actividades de ocio, preferencias estéticas, hobbies, vestimenta, hábitos, intensidad de uso de la calle, permisividad de los padres, etc. - evidencia una discriminación sectaria (Nadja Monnet, 2002)14: "una amiga me dijo que no le gustaban los marroquíes porque el color de piel que tienen es feo. Le dije: mira, yo soy más oscura que ellos y no me dices nada. Me di cuenta que también era clasismo. Piensan: ella es así pero es de otra clase social... eso no me gusta" [Abril, 17 años].

En ese sentido, los trayectos urbanos implican un movimiento dentro de las categorizaciones sociales como sexo, fenotipo, clase, etc. Los peatones utilizan estos referentes como pautas clasificatorias para sus interacciones. Se trata de un cúmulo de herramientas usadas para orientar sus percepciones, emociones y acciones en los espacios públicos. La construcción social del otro y de sí mismo motiva las rutas, las evitaciones o las frecuentaciones de los lugares y la forma en que todo esto es vivido.

En relación con ese tipo de decisiones, resalta el temor que infunden los callejones sin salida en la mayoría de nuestros interlocutores, lo cual les lleva a evitarlos. En su análisis de la construcción social del miedo, Hile Koskela (2011) advierte que este tiene diversas fuentes. No obstante, da un lugar relevante a las advertencias de los padres, a los rumores y a la información ofrecida por los medios de comunicación. Sin embargo, es importante resaltar la capacidad de agencia de niños y jóvenes. Marie-Axelle Granié subraya este aspecto cuando dice que "el niño no aprende las reglas sociales de forma pasiva; al contrario, muy tempranamente trata de comprender su sentido y, en consecuencia, construye una distinción entre ellas, basada en su experiencia en el marco de las interacciones sociales" (Granié, 2010: 94). Esto significa que las pautas sociales no solo provienen de los padres u otros adultos encargados de su educación, también proceden de su propia experiencia en solitario o compartida con sus compañeros. Es esta una observación aplicable a la configuración de las percepciones sobre el otro y su lugar en el espacio social.

Tal como apunta Koskela "el miedo también tiene dimensiones espaciales [...] tiene una realidad socialmente producida. Está profundamente relacionado con las configuraciones de raza, clase, edad - y sobre todo con el género" (Koskela,

14 Este es un mecanismo bien conocido cuando se analizan actitudes racistas. Quienes lo aplican, adjudican juicios de valor a un grupo que se desprecia, pero excluyen de esta adjudicación a la persona conocida. 
2011: 274). La mayoría de nuestros interlocutores más jóvenes [10 a 13 años] tienen miedo de los callejones sin salida; niños y jóvenes comparten el temor a los callejones oscuros que evitan. Los chicos temen ser asaltados, que alguien se los lleve o les pegue. Además, se enfrentan a los modelos estereotipados de lo que deber ser un hombre: durante un recorrido hacia una fiesta de cumpleaños, la madre de uno de los participantes cuenta que su hijo y un amigo son catalogados como gays por algunos de sus compañeros. Esta adjudicación se da por el hecho de 'ser suaves' y tener amigas. Por otro lado, también destaca el miedo y la molestia de las chicas frente al acercamiento verbal o físico de hombres de distintas edades en los espacios públicos; temor y rechazo que también experimentan en las redes sociales como Facebook y WhatsApp.

Si en los espacios públicos toman cuerpo las tensiones sociales, también podemos observar iniciativas de resolución de los conflictos. Varias de las participantes refieren episodios de acercamiento de hombres desconocidos en la calle: una de ellas cuenta que un hombre mayor la sigue en su coche, se detiene y le pregunta si es latina. Otra de ellas explica cómo fue acosada por un comerciante del barrio quien, aprovechando una emergencia en la cual él le presta su teléfono, se queda con su número y la llama para quedar [ella se asusta y recurre a su padre quien habla con el comerciante]. Una más relata que ha recibido frases intrusivas muy desagradables, incluidos piropos, mientras otra refiere la irrupción de desconocidos que quieren quedar a través de Facebook y WhatsApp. Algunas de nuestras interlocutoras también comentan haber experimentado las redes sociales como escenario de insulto y amenazas en situaciones de tensión, por parte de la ex-pareja o compañeros con quienes tienen algún conflicto.

De acuerdo con las interlocutoras, esa invasión del cuerpo femenino genera una sensación de vulnerabilidad que las lleva a estar atentas en sus recorridos en solitario, a pesar de concebir los espacios públicos como abiertos y disponibles para todos. Pese a esa invasión, deciden acceder, usar y construir los espacios públicos y, con ello, introducen cambios en las relaciones marcadas por los roles establecidos. Esto significa una negociación del derecho a los espacios vedados y una confrontación de los tránsitos conflictivos, que podemos interpretar como iniciativas para resistir y transgredir los usos hegemónicos de los territorios. Para hacerlo, utilizan estrategias como la evitación; pero también haciendo frente con el propio cuerpo — negándose a evitar lugares - aunque eso signifique enfrentar el miedo. Una de nuestras interlocutoras es enfática al afirmar que no deja de transitar las calles ni las rutas que le parecen más cortas, a pesar de experimentar miedo a las agresiones verbales de un grupos de chicos que encuentra siempre de camino a su instituto. Tampoco ha dejado de caminar por la calle en donde fue seguida varias veces por un hombre con estética gótica, ni deja de atravesar una plaza de paso obligado al colegio, donde asegura hay chicos consumiendo drogas. A pesar de esos encuentros frecuentes, decide transitar, recorrer y estar en espacios donde se siente en tensión. Esta actitud $-\mathrm{y}$ la de otras participantes, que a pesar de tener miedo a la oscuridad de la calle, salen por la noche- es muy significativa: representa la persistencia en materializar el derecho a la ciudad por parte de las jóvenes. Por tanto, implica un impacto en las masculinidades que deben re-interpretar y negociar nuevos valores que trastocan las relaciones de género establecidas (Monnet, 2007). 


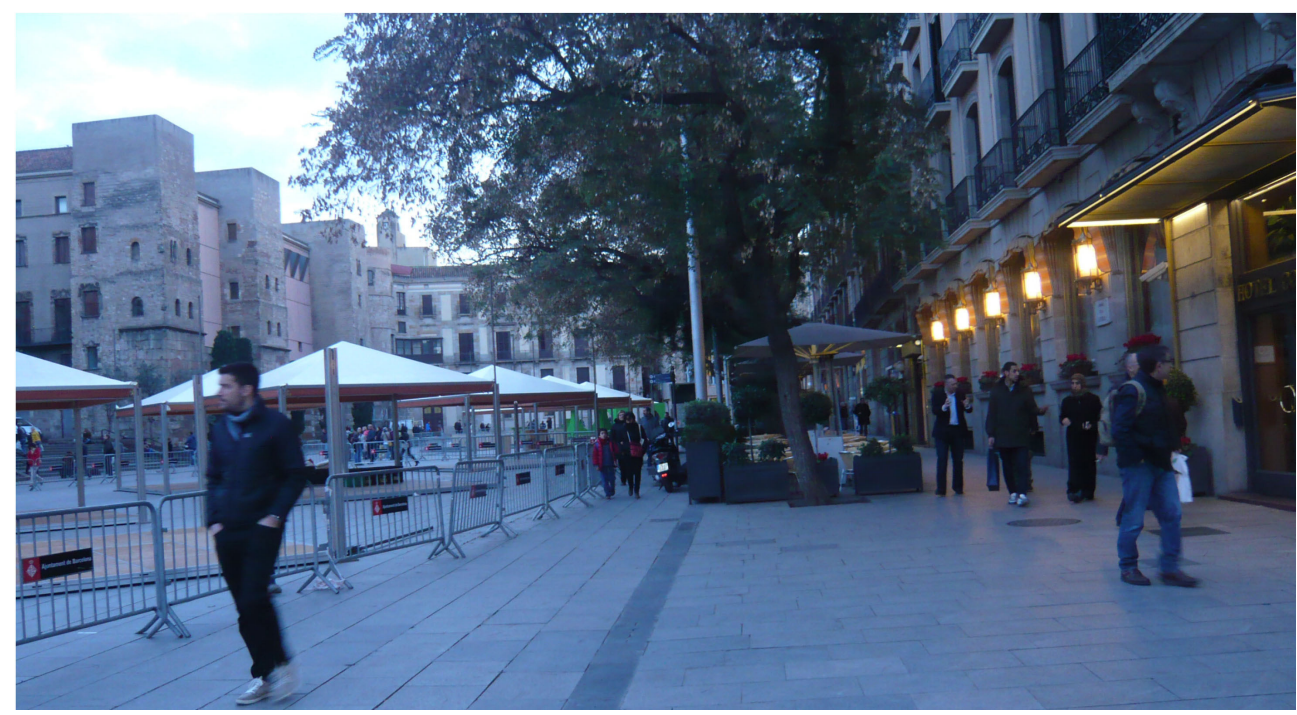

Imagen 2. "Este sitio me gusta porque siempre hay gente y nunca me va a pasar nada"

[Sabina, 15 años]. Los espacios abiertos, de tránsito constante y bien iluminados, son descritos como seguros por la mayoría de los participantes. Fotografía de Sabina.

\section{El paseo como digresión}

Al comenzar el trabajo de campo categoricé los trayectos como pautados o de ocio, pero a medida que avancé apareció el tema de los paseos. Deambulaciones para ir a "ventilarse", "tomar el fresco" o "liberar la mente" del ambiente agobiante del hogar o de los conflictos personales. Es el caso de Laura [20 años], quien dice estudiar mejor en la calle que en casa, donde la presencia de sus padres le impide concentrarse.

Otras participantes manifestaron encontrar en la calle una forma de explorar su intimidad. Paradójicamente, cuando realizan caminatas en solitario ${ }^{15}$ pueden sumergirse en su interioridad en medio del bullicio de la calle. Paseos, derivas, deambulaciones... "cuando estoy triste, necesito pensar. Entonces vengo por aquí, miro, observo y me voy hacia el puerto" comenta Laura, de 20 años. Hace este recorrido específico cuando se siente triste; se trata de una "geografía afectiva", diría David Le Breton (2015: 83). Laura experimenta un mundo de sensaciones y recuerdos mientras camina hacia el mar: el olor de la paella en las Ramblas, los cuadros expuestos en ese paseo... hace una fotografía del Museo de Cera que la conecta con su infancia; y se dirige al puerto donde escucha las gaviotas, y el ruido de los palos de los barcos mecidos por el viento, para terminar sentada frente al agua. Este trayecto muestra un uso intimista de los recorridos como forma de "pensar en mis cosas".

15 Ninguno de los chicos expresó este uso intimista de los paseos. En cambio, los ven como una forma de llegar a los puntos de interés: visitar tiendas de móviles, caminar mientras charlan con los amigos, mirar productos informáticos incluidos videojuegos y otras actividades también practicadas por las chicas como ir a comprar caramelos, explorar otras zonas de la ciudad, encontrarse con amig@s en su casa o en la calle, ir al cine, a la playa, etc. 
Algo parecido expresa Lorena [20 años]: "Si estoy mal, salgo a la calle para ver cosas que me distraigan un poco". La calle como espacio de libertad e intimidad también es mencionada por Laia [15 años]: "nadie me dice si estoy pensando bien o mal". Todas las participantes describen estos recorridos emocionales como reflexivos; como una forma de distraerse de lo que les preocupa. Esto nos lleva a concluir que la fragmentariedad de acontecimientos que recorren, se convierte en una fórmula para situarse frente a lo que les ocurre.

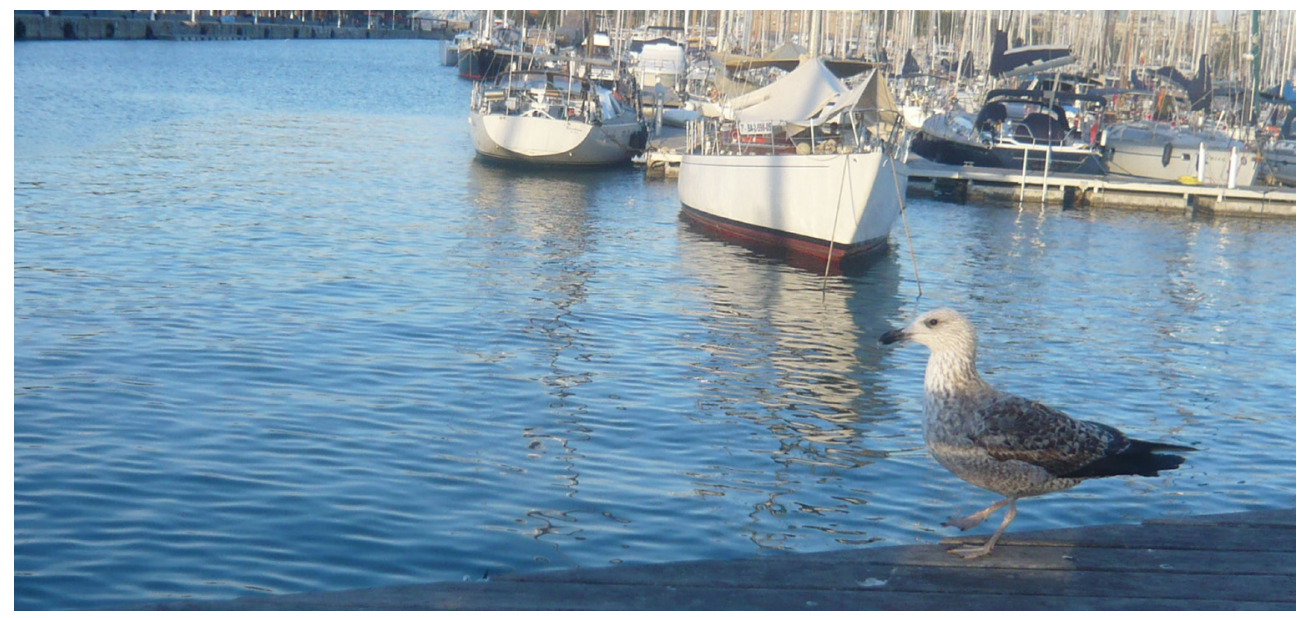

Imagen 3. "El sonido de los palos de los barcos me relaja" [Laura, 20 años]. Las derivas se tejen de retazos extraídos de la polifonía de los espacios públicos. Fotografía de Laura.

Nuestras caminatas con los interlocutores no estuvieron exentas de "momentos paseo", en los cuales nos quedábamos en silencio, cada quien pensando en "sus cosas". Y, en ocasiones, también permitían encontrar formas indirectas de abordar las cuestiones relacionadas con la investigación.

\section{Memoria y silencio}

La acción, las palabras y el silencio son la materia prima de los recorridos acompañados, donde son importantes la conversación, los relatos y los recuerdos. Jean-Yves Petiteau (2008) hace una distinción entre la memoria voluntaria que "recompone el pasado a partir de los presentes" y la involuntaria ${ }^{16}$ que "reposa en la semejanza entre dos sensaciones o dos momentos". Durante los recorridos acompañados observamos y escuchamos ese contacto entre pasado y presente a través de la memoria, asistimos a la reconstrucción de hechos a partir de nuestras preguntas. Pero también recibimos comentarios imprevistos, desatados por el camino, la conversación, el estado de ánimo o las emergencias de lo urbano.

16 Petiteau (2008) rescata el concepto de memoria involuntaria acuñado por Deleuze a partir de su lectura de la obra de Marcel Proust. 
La memoria involuntaria, suscitada por elementos emergentes e involuntarios, permite proximidad con los interlocutores: al divisar la estatua de Cristóbal Colón, uno de ellos explica la responsabilidad de los Reyes Católicos en la situación actual de los países violentados por el colonialismo. Otra de nuestras participantes recuerda un sueño recurrente sobre el día que sus padres fueron por ella al orfanato. Mientras estamos sentadas en un banco de camino a su entrenamiento de fútbol, al ver pasar un coche relata ese sueño en el que sus padres llegan en un auto verde, similar al que ve pasar. En ese sentido, los recorridos implican una actualización de elementos que resultan insondables en una entrevista, gracias a los estímulos propios de lo imprevisto, que despiertan la memoria involuntaria.

El carácter selectivo de la memoria constituye un elemento de la acción y por tanto de la interacción. Jean-François Augoyard (2010: 35) subraya que en la vida cotidiana no se recurre solo a la memoria respecto a hechos pasados. Considera que "también hay una memoria que actúa en el presente". Al lado de esta memoria "retentiva", se encuentra la memoria que el autor llama "protensional"; describe esta última como "aquella mediante la cual organizamos nuestras percepciones según lo memorable a construir [...] En el presente, la memoria [protensional] es el "mañana" de lo vivido actual" (Augoyard, 2010: 35). El autor propone estar atentos no solo a la memoria del pasado sino también a la que se está construyendo sobre la marcha - o, mejor dicho, en nuestro contexto, durante la marcha_- Según su perspectiva hay que captar la memoria en el momento en que se constituye, "en el momento en que esta organiza la expresión de una manera de ser que se podrá restituir más tarde [...] Porque no se puede comunicar nada de la vida cotidiana si lo percibido no es memorable" (ibídem). Como se ha apuntado antes, las cartografías marcadas por los discursos hegemónicos reiteran los estereotipos y los rumores, pueden pasar a formar parte de esa memoria "protensional" para un uso limitado o temeroso de la calle; pero también pueden ser puestas en cuestión a través del cuerpo mediante usos transgresores que generan una re-negociación de los lugares adjudicados en las jerarquías construidas socialmente.

A propósito de lo anterior, Jesús María De Miguel advierte que "La variable tiempo, así como la variable memoria son esenciales para entender la realidad social" (De Miguel, 2004: 13). El autor habla de los "missing", es decir, los temas de los cuales no se habla o las razones por las cuales no se dicen ciertas cosas. Subraya que se investiga muy poco sobre lo oculto, lo que se olvida. Advierte que, a menudo, los "missing" se descubren por casualidad o, mejor dicho, por serendipia ${ }^{17}$, como ocurre cuando se utiliza la metodología del recorrido acompañado.

Anne-Marie Losonczy (2002) también destaca la importancia del silencio en el trabajo de campo. Argumenta que este ofrece un espacio de intercambio y negociación para la construcción conjunta del conocimiento, donde también tienen valor los aspectos emocionales de la relación entre los participantes y el etnógrafo. Según la autora, el silencio es un pacto que permite acercamiento entre las partes, donde la observación mutua sirve para tejer la relación que implica el trabajo en el terreno. El silencio genera una complicidad que permite acuñar preguntas menos directas y

17 El etnógrafo debe estar atento a la emergencia de estos momentos. Para ello, resulta útil el concepto de "observación flotante", que consiste en prestar atención a los imprevistos, las variaciones y todos los elementos propios de la liquidez de los espacios públicos (Colette Pétonnet, 1982). Más recientemente, Clark y Emmel (2010) subrayan la importancia de la serendipia, a la luz de sus trabajos sobre vecindarios y comunidades donde utilizan la entrevista caminando [walking interview]. 
diálogos más cercanos... nos conduce a hallazgos insospechados. La singularidad de este saber compartido, siempre en construcción y en parte imprevisible, proviene del rol productivo que juegan los malentendidos (Losonczy, 2002: 95). Compartir el silencio permite explorar y ser explorado, entrar en relaciones donde el cuerpo también dice y actúa. De igual forma, incide en la lentitud que permite rumiar las palabras, los gestos, los silencios del otro; nos remite hacia una configuración personal que genera memoria de doble vía -incluida la reflexión y la revisión en el análisis del trabajo de campo-; porque el silencio, poblado de gestos, representa un entramado de sentido que podemos observar y analizar.
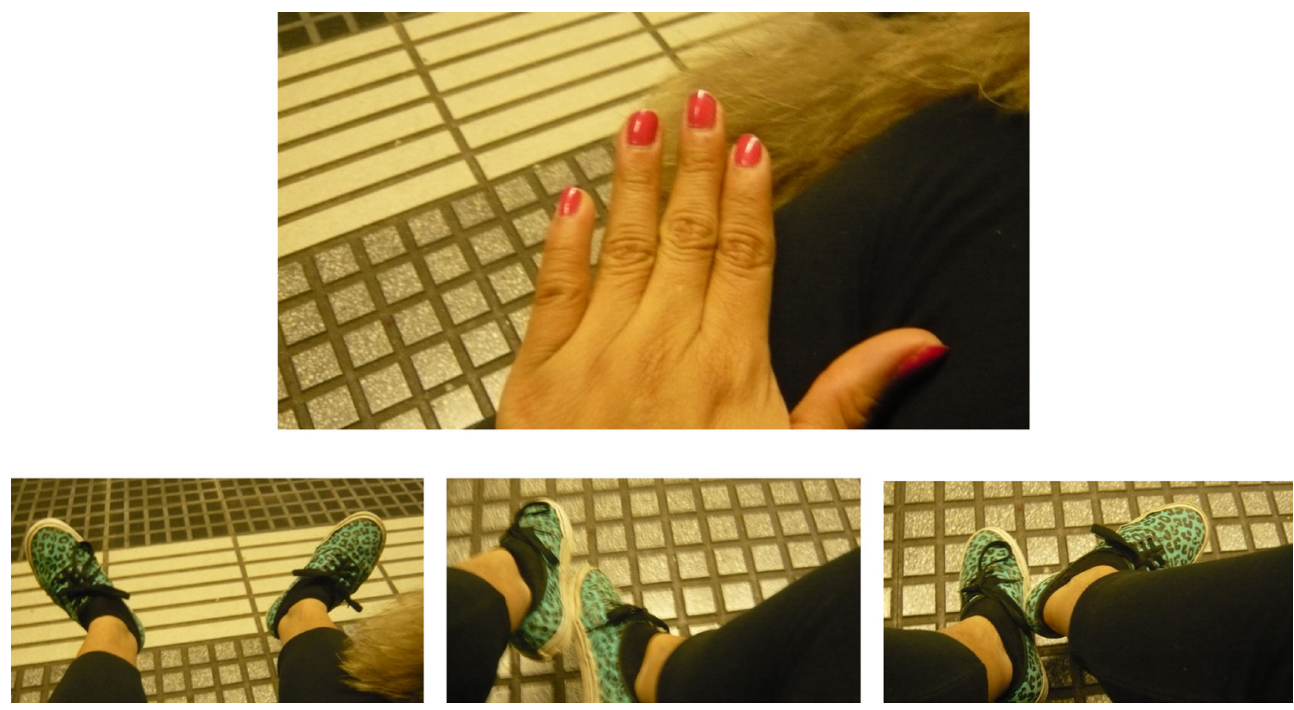

Imagen 4. Escuchar el silencio de los participantes — con cámara en mano- también dio vía libre a la exploración de su propia imagen. Varias participantes realizaron este tipo de fotografías fragmentadas de su cuerpo durante las caminatas. En este caso esperábamos un metro para ir al centro a deambular por las tiendas de ropa. Fotografía de Carla [15 años].

La escucha activa - incluida la del silencio - es una pieza fundamental del recorrido acompañado: escuchar y observar el silencio es indisociable de esta metodología porque la ausencia de palabras siempre es plausible en las caminatas con otro. El silencio es tan importante como la palabra en la metodología de los recorridos acompañados: respeta el ritmo de la interacción; constituye una forma de encontrar nodos de tensión; establece nexos de proximidad y es un espacio de negociación sobre lo que el interlocutor quiere decir o no: "El silencio es una modalidad del sentido, un sentimiento que atrapa al individuo" (Le Breton, 2015: 31). Cabe recordar aquí, cómo algunos de esos momentos de silencio eran rotos por el canto de nuestros interlocutores, unos como muestra de cercanía y confianza, otros como deseo de alejamiento. En palabras de Le Breton: "El canto es un compañero de ruta, un balancín mental, y el vagabundo se libera con él de todos los usos y costumbres" (2015: 38). 


\section{De la etnografía en movimiento a la dimensión resiliente del andar}

A través de la metodología del recorrido acompañado he podido explorar la agencia de niños y jóvenes adoptados en espacios públicos y semi-públicos ${ }^{18}$. Más allá de nuestra búsqueda por su gestión frente a la discriminación, experimentada por sus rasgos físicos, he accedido a sus prácticas caminatorias y a su visión de la ciudad - sin decir que su forma de practicar los espacios urbanos sea distinta a la del resto de jóvenes y niños barceloneses.

La metodología del recorrido acompañado me ha permitido abordar temas como la autonomía, la perpetuación de los estereotipos de género y "raza", el miedo, el impacto de la clase en la construcción del otro, así como la mirada plástica y política de los participantes. Este mapa de datos es posible gracias a la particularidad del acompañamiento de recorridos: por las relaciones que se establecen, por las facetas de la memoria que despiertan, por el sentido de lo dicho y de lo no dicho. "El itinerario no es solamente un desplazamiento en el territorio del otro, es, al mismo tiempo, un desplazamiento por su universo de referencias", comenta Petiteau y Pasquier (2001: 65), por ello, resulta plausible concluir que la etnografía en movimiento es un ejercicio de construcción conjunta del conocimiento, a partir de la caminata compartida por investigador y participantes.

La metodología del recorrido acompañado asume el papel de agencia y gestión del conocimiento del otro. En el caso de niños y jóvenes permite explorar su voz como insumo para una construcción de la ciudad que les tenga en cuenta como sujetos. Esto obliga a revisar la construcción de niños y jóvenes como inmaduros y en formación, así como a tener en cuenta su lugar como interlocutores. Tal como apuntan Marie-Soleil Cloutier y Juan Torres (2010: vii), "podemos preguntarnos ya no tanto sobre el impacto de la ciudad sobre el niño, sino más bien sobre la manera en que la experimenta y puede ser transformada en un mejor lugar para crecer". Esto añade una dimensión ética y política para investigadores, comunidad educativa y legisladores. Mientras los niños y jóvenes estén ausentes como agentes en las relaciones familiares, la escuela y el Estado, las transformaciones que ofrecen sus miradas permanecerán en el olvido. Es imperativo que el mundo de los adultos vuelque también su mirada sobre estos aspectos. Retomando a Cloutier y Torres, "los niños, contrariamente a otros grupos de adultos marginados - como las mujeres o las minorías étnicas - no tienen la posibilidad de participar en los procesos de toma de decisiones. Para paliar esta carencia, necesitan aliados" (Matthews y Limb, citados por Cloutier y Torres, 2010: xii).

18 El patio de la escuela, algunos recintos de actividades extra escolares, acontecimientos abiertos al público, manifestaciones cívicas, entre otros, así como espacios más íntimos como su casa o la de algún familiar. 


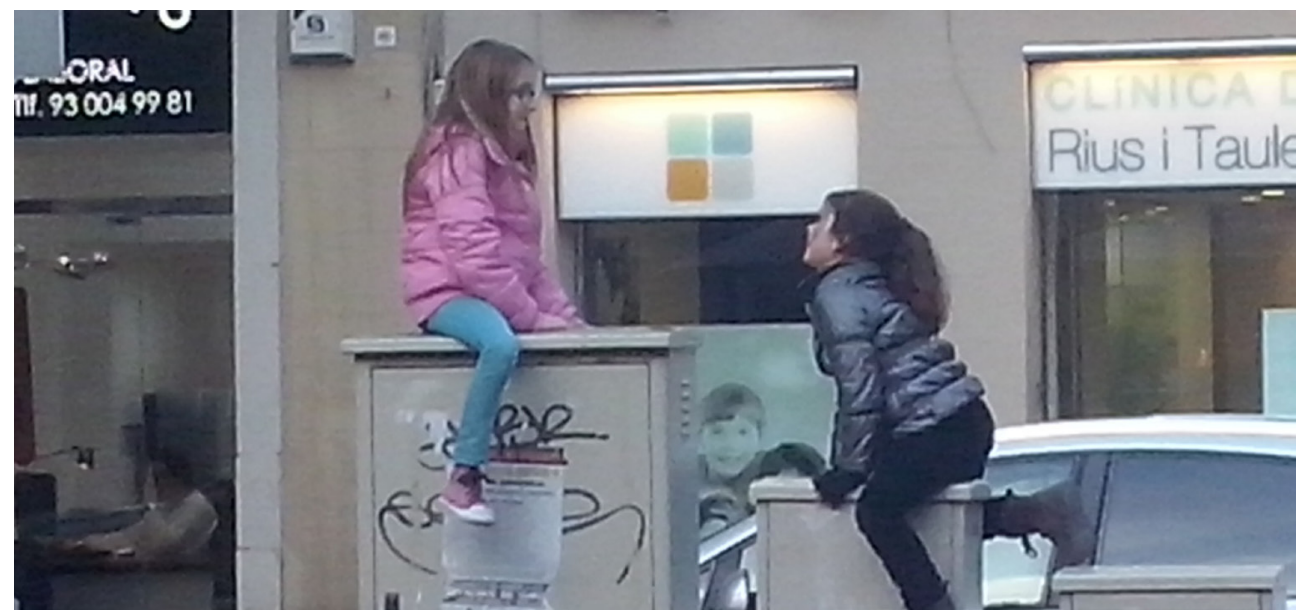

Imagen 5. Observar los usos subversivos de los espacios públicos también ofrece insumos para las políticas públicas urbanas. La mayoría de los participantes manifestaron aburrirse con los espacios de ocio que les ofrece la calle y la falta de mobiliario y espacios públicos que les permitan disfrutar de la ciudad.

Reivindicar la agencia política de niños y jóvenes significa restituir su derecho a la ciudad, planteado por Naciones Unidas en la Convención de los Derechos del niño, así como en varias Asambleas, Cumbres y en la Agenda 21. En todos esos documentos se resalta el papel activo de niños y jóvenes en la toma de decisiones: "Se ha reconocido que los niños representan una proporción importante de la población urbana y que su participación en la toma de decisiones que conciernen a su entorno inmediato es provechosa [United Nations, 2006]" (Cloutier y Torres, 2010: x).

La etnografía en movimiento sigue siendo minoritaria, pero no por ello menos eficaz a la hora de aportar en el conocimiento de los usos de las ciudades y dar la palabra a los copartícipes de la gestión de ese conocimiento. Igualmente, otras disciplinas han utilizado el andar como método, en la enseñanza - arquitectura-; en la consulta ciudadana para la recuperación de espacios — poderes políticos locales-; en el tratamiento de la depresión y el parkinson —neurología-; en la redirección de la trayectoria profesional - coaching - y en la intervención con jóvenes en situación de riesgo por su conducta delictiva o su dependencia de los estupefacientes - trabajo social- David Le Breton comenta una de estas experiencias recogidas en el libro escrito con Daniel Marcelli y Bernard Olliver, prologado por Boris Cyrulnik. En ese trabajo se presenta la experiencia de una asociación ${ }^{19}$ que realiza caminatas de varios kilómetros con jóvenes de entre 15 y 18 años que han salido de la cárcel o aún están allí. Los directores de la organización no pretenden encontrar la solución a los conflictos de los chicos, pero encuentran en el andar una forma de paliar sus tensiones internas: "Simplemente tratamos de trabajar apoyándonos en el efecto energético y socializador de la marcha a pie" (Olliver, 2012: 14).

Boris Cyrulnik — quien ha trabajado el tema de la resiliencia durante más de 20 años - considera que no hay que inventar un nuevo concepto para referirse a

19 L'association Seuil: http://www.assoseuil.org 
algo que el ser humano ha utilizado desde el inicio de la humanidad para salir del paso (Cyrulnik, 2012: 7). Tras dos décadas de debates en torno al término, Cyrulnik describe la resiliencia como "el arte de navegar en los torrentes [...] el resiliente ha de hacer un llamamiento a los recursos internos que se hallan impregnados en su memoria $[. .$.$] hasta el momento en que una mano tendida le ofrezca un recurso$ externo" (Cyrulnik, 2002: 209). Esta concepción de la resiliencia llama al individuo, a la familia y a la sociedad en su conjunto a luchar contra los prejuicios y las prácticas culturales inequitativas (Cyrulnik, 2011). La experiencia terapéutica del andar, como forma de restituir el lugar social digno a los jóvenes, implica una negociación que solo se puede dar en relaciones de equidad porque "El vínculo social implica un mínimo de confianza que sólo la reciprocidad autoriza” (Le Breton, 2012: 47).

Aunque la propuesta explicada por Le Breton, Marcelli y Olliver (2012) utiliza recorridos largos y en medio de paisajes naturales, durante nuestra etnografía observamos la capacidad transformadora de los recorridos acompañados de duración menor y en espacios urbanos. Tal como señala Le Breton, refiriéndose a la experiencia con los jóvenes, la presencia de un adulto refuerza el significado de la caminata porque evidencia las repercusiones de los propios actos sobre los demás, porque es una presencia que no juzga sino "la presencia de alguien mayor que no está ahí para "vengar" la "sociedad" sino para permitir al joven su avance en un conocimiento más profundo de sí mismo" (Le Breton, in: Le Breton, Marcelli y Olliver, 2012: 47).

Este aspecto reparador del andar también se evidenció en nuestro trabajo de campo. Uno de nuestros interlocutores, que respondía con monosílabos y evasivas, expresó durante uno de los recorridos las causas de su malestar en la escuela. Asimismo, algunas madres mencionaron la cualidad reparadora del andar de nuestro trabajo de campo. Fue así como, al finalizar la serie de recorridos con participantes de una misma familia, la madre dijo:

\begin{abstract}
"Quiero agradecerte porque tus salidas con los niños han sido terapéuticas, han llegado muy tranquilos, relajados, contentos. Eres una figura rara porque eres un adulto no familiar que ha creado empatía con ellos. Con lo que haces he descubierto que es mejor salir a caminar con los chicos cuando hay tensión o frente a un dilema, porque sentarles a hablar no funciona. Deberías crear una terapia aplicando la metodología que empleas para la investigación” [Marta, 48 años].
\end{abstract}

Algo parecido sucedió mientras otra madre me acompañaba para tomar mi ruta de vuelta a casa. Durante el trayecto, ella explica algunos problemas que tiene con su hijo y que no puede compartir con nadie más. El chico finalmente abandona la investigación. Para comunicármelo, la madre escribe un mensaje por WhatsApp con la invitación de volver a vernos "para hacer terapia” [Elisa, 49 años].

Concluimos con esto que la etnografía en movimiento permite superar algunas limitaciones de la entrevista en el ámbito de la antropología urbana, vuelve central y activos a los participantes en la investigación y aporta elementos para la construcción de una ciudad que escucha a todas las minorías, especialmente aquellas que hemos confinado al silencio por su construcción como actores pasivos: lo que niños, niñas y jóvenes tienen para decir en torno a las cuestiones y tensiones sociales que se evidencian en los espacios públicos. 


\section{Referencias bibliográficas}

Anderson, Jon (2004). “Talking whilst walking: a geographical archaeology of knowledge”. Revista Area, 36(3), 254-261. Londres: Royal Geographical Society (with The Institute of British Geographers). doi: http://dx.doi.org/10.1111/j.0004-0894.2004.00222.x

Arias, Diana (2000). El recorrido como micro-fenómeno social. Tesina de Máster inédita. Facultad de Geografía e Historia, Departamento de Antropología Social y Cultural. Universidad de Barcelona.

Audas, Nathalie; Martuzet, Denis (2009). "Saisir l'affectif urbain. Proposition originale par la cartographie de réactivation des discours". Actes du colloque Penser la ville - approches comparatives (Khenchela, Algeria, Oct 2008): 62-77. <halshs-00380553> Web 29/07/ 2015. https://halshs.archives-ouvertes.fr/halshs-00380553/document

Augoyard, Jean-François (2010 [1979]). Pas à pas; essai sur le cheminement en milieu urbain. Tours: A la Croisée ( $2^{\mathrm{a}}$ edición).

Berenstein, Paola (2012). Elogio aos errantes. Salvador: EDUFBA.

- (2006) "Errances urbaines: l'art de faire l'expérience de la vie; autres chemins contre la spectacularisation urbain", en P.-H. Jeudy, P. Berenstein (eds), Corps et décors urbains: les enjeux culturels des villes. Paris: L'Harmattan, 103-116.

Christensen, Pia y O'Brien, Margaret (2003). Children in the city. RoutledgeFalmer. London y New York.

Clark, Andrew; Emmel, Nick (2010). "Using walking interviews". Realities Toolkit [No. 13]. Morgan Centre, Sociology, University of Manchester: http://eprints.ncrm. ac.uk/1323/1/13-toolkit-walking-interviews.pdf

Cloutier, Marie-Soleil; Torres, Juan (Eds.) (2010). "L'enfant et la ville; notes introductoires". Enfances, Familles, Générations n¹2: i-xv. doi: 10.7202/044389ar

Cyrulnik, Boris (2011 [1999]) Resilience: How Your Inner Strength Can Set You Free from the Past. Chicago: Paperback.

- (2002) Los Patitos feos. La resiliencia: una infancia infeliz no determina la vida. Barcelona: Gedisa.

De Biase, Alessia (2006) "Ruses urbaines comme savoir", en P.-H. Jeudy, P. Berenstein (Eds.), Corps et décors urbains: les enjeux culturels des villes. Paris: L'Harmattan, 91-100.

De Certeau, Michel (1990 [1980]). L'invention du quotidien. 1. Arts de faire. Paris: Éd. Gallimard, coll. folio essays.

Delgado, Manuel (1999). El animal público. Barcelona: Anagrama.

De Miguel, Jesús-Maria (2004) "La memoria perdida". Revista de Antropología Social, No. 13: 9-35. Madrid: Universidad Complutense de Madrid. http://revistas.ucm.es/index.php/ RASO/article/view/RASO0404110009A

Granié, Marie-Axelle (2010). "Socialisation au risque et construction sociale des comportements de l'enfant piéton: éléments de réflexion pour l'éducation routière". Enfances, Familles, Générations, nº 12: 88-110. doi: 10.7202/044394ar

Huguenin-richard, Florence (2010). "La mobilité des enfants à l'épreuve de la rue. Impacts de l'aménagement de zones 30 sur leurs comportements". Enfances, Familles, Générations, $\mathrm{n}^{\circ}$ 12: 66-87. doi: 10.7202/044393ar

Joseph, Isaac (1998). Retomar la ciudad. Medellín: Universidad Nacional de Colombia.

Koskela, Hille (2011). "El desafío del miedo — delito y miedo al delito como problemas sociales urbanos". Brazilian Geographical Journal: Geosciences and Humanities research medium, Uberlândia, 2 (2)( jul./dec.): 274-285. http://www.seer.ufu.br/index. php/braziliangeojournal/article/viewFile/13711/8103 
Kusenbach, Margarethe (2003). "Street Phenomenology. The Go-Along as Ethnographic Research Tool”. Ethnography 4(3): 455-485.

Le Breton, David (2015). Elogio del caminar. Madrid: Siruela.

-; Marcelli Daniel; Ollivier, Bernard (2012). Marcher pour s'en sortir. Toulouse: Éditions Érès.

Legué, Pascale (2015). “Des villes pour les enfants?”, en Th. Paquot (ed.) La ville récréative, Gollion: CH: In folio, 45-58.

Losonczy, Anne-Marie (2002). "De l'énigme réciproque au co-voir et au silence", en Ch. Ghasarian (Ed) De l'ethnographie à l'anthropologie réflexive. Paris: Armand Colin, 91102.

Monnet, Nadja (2002) La formación del espacio público: una mirada etnológica sobre el Casc Antic de Barcelona. Madrid: Catarata.

- (2007). La ciudad, instrucciones de uso. Esbozos Barceloneses. Tesis doctoral. Facultad de Geografía e Historia. Departamento de Antropología Social y Cultural Universidad de Barcelona.

—; San Román, Beatriz; Marre, Diana (2016). "Étrangers dans leur ville; les jeunes issus de l'adoption internationale dans la ville de Barcelone ". Ethnologie française, XLVII, $\mathrm{n}^{\circ} 2$, 335-346. doi: https://doi.org/10.3917/ethn.162.0335

Petiteau, Jean-Yves (2008) "La méthode des itinéraires ou la mémoire involontaire”, en A. Berque, A. De Biase and Ph. Bonnin (eds) L'habiter dans sa poétique première [Actes du colloque de Cerisy-La-Salle]. Paris: Editions Donner Lieu, 102-115.

—; Pasquier, Elisabeth (2001). "La méthode des itinéraires: récits et parcours", en: M.

Grosjean, J.-P. Thibaud (Eds.) L'espace urbain en méthodes. Marseille: Ed. Parenthèses, 6378.

Pétonnet, Collette (1982). “L'observation flottante: l'exemple d'un cimetière Parisien". L'Homme (Paris) 22 (4): 37-47.

Rasmussen, Kim (2004). "Places for children - children's places". Childhood. SAGE Publications. London, Thousand Oaks and New Delhi, Vol 11(2): 155-173.

Sansot, Pierre (1996 [1971]). La poétique de la ville. Paris: Armand Colin.

Tarrius, Alain (1989). Anthropologie du Mouvement. Caen: Paradigme.

Thibaud, Jean-Paul (2001). "La méthode des parcours commentés”, en M. Grosjean and J.-P.

Thibaud (Ed.) L'espace urbain en méthodes. Marseille: Ed. Parenthèses, 79-99. 